\title{
Antimicrobial and Antioxidant Activity of the Biologically Synthesized Tellurium Nanorods; A Preliminary In vitro Study
}

\author{
Mojtaba Shakibaie ${ }^{1,2}$, Mahboubeh Adeli-Sardou ${ }^{1}$, Tayebe Mohammadi-Khorsand ${ }^{2}$, Mahdie Zeydabadi- \\ Nejad ${ }^{3}$, Ehsan Amirafzali ${ }^{3}$, Sahar Amirpour-Rostami ${ }^{2}$, Atefeh Ameri ${ }^{2}$, Hamid Forootanfar ${ }^{2,4,}$ * \\ ${ }^{1}$ Herbal and Traditional Medicines Research Center, Kerman University of Medical Sciences, Kerman, Iran \\ ${ }^{2}$ Pharmaceutics Research Center, Institute of Neuropharmacology, Kerman University of Medical Sciences, Kerman, Iran \\ ${ }^{3}$ The Student Research Committee, Faculty of Pharmacy, Kerman University of Medical Sciences, Kerman, Iran \\ ${ }^{4}$ Department of Pharmaceutical Biotechnology, Faculty of Pharmacy, Kerman University of Medical Sciences, Kerman, Iran \\ "Corresponding author: Hamid Forootanfar, Pharmaceutics Research Center, Institute of Neuropharmacology, Kerman University of Medical Sciences, \\ Kerman, Iran. Tel.: +98 34 31325238, Fax: +98 34 31325003. E-mail: h_forootanfar@kmu.ac.ir \\ Received: 7 May 2016; Revised: 27 February 2017; Accepted: 8 October 2017; Published online: 29 December 2017
}

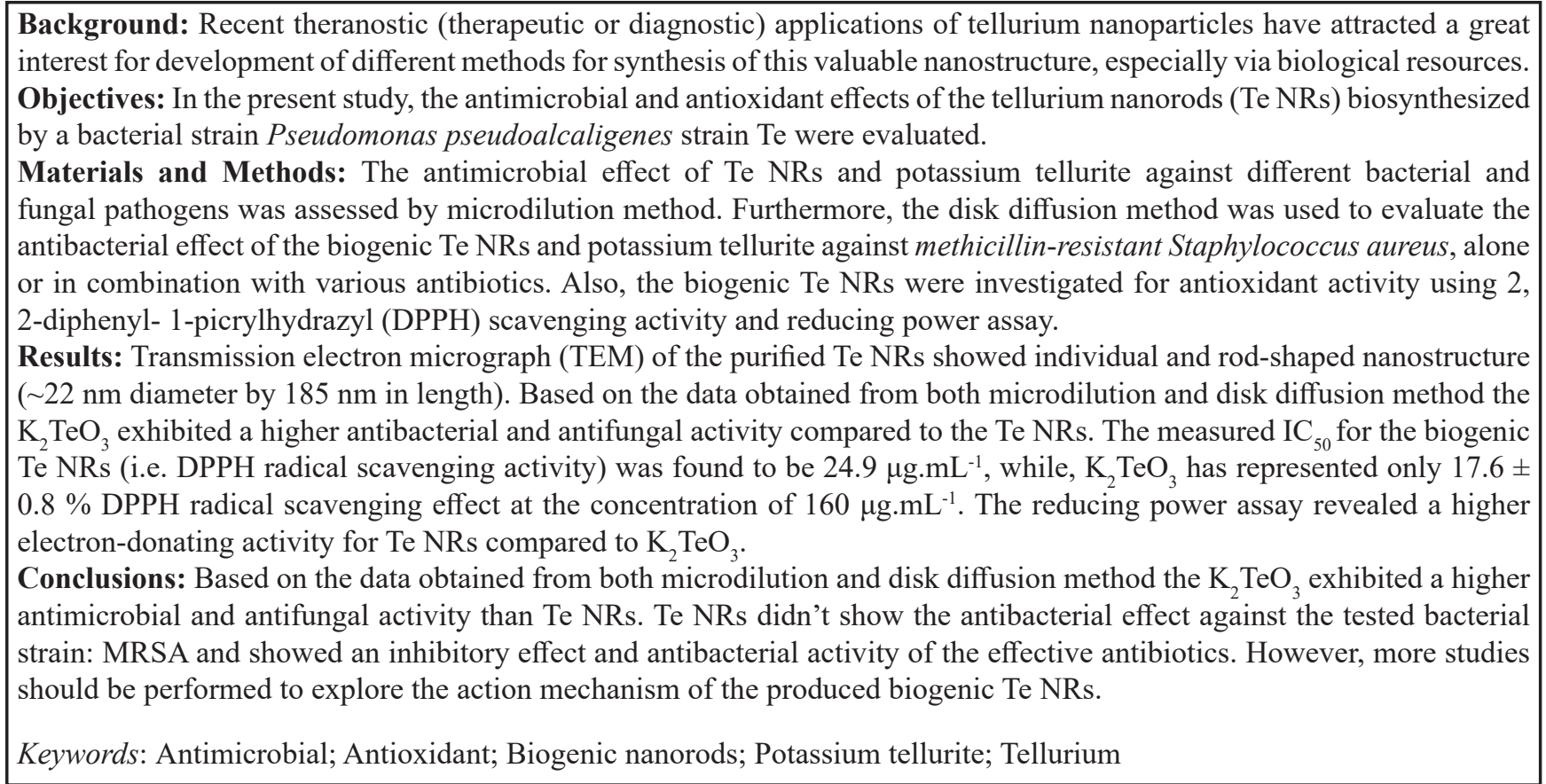

\section{Background}

Tellurium (Te) is a non-essential biological metalloid element which belongs to the group of chalcogens (1). Unlike selenium; its relative, the biological and the medical properties of the tellurium and its compounds have rarely been evaluated (2). Among the different oxidation states of the Te, only elemental tellurium (i.e., $\mathrm{Te}^{0}$ ) is insoluble in the water and can be arranged at the nanoscale by the biological or chemical reduction of the higher oxidation states of Te such as tellurite
$\left(\mathrm{TeO}_{3}{ }^{2-}\right)$ and tellurate $\left(\mathrm{TeO}_{4}{ }^{2-}\right)(3,4)$. Although the potential toxicity of $\mathrm{Te}^{0}$ has not been fully understood, the bactericidal activity of the Te oxyanions has been recognized since the discovery of antibiotics. Reviewing the literature, it was found that the toxicity of the tellurite occurs via the two probable mechanisms: i) replacing the sulfur group in a number of amino acids and as a result creating non-functional proteins and ii) severely oxidizing the glutathione reservoir of the cells, which lead to the generation of excessive amounts of reactive

Copyright (C) 2017 The Author(s); Published by National Institute of Genetic Engineering and Biotechnology. This is an open access article, distributed under the terms of the Creative Commons Attribution-NonCommercial 4.0 International License (http://creativecommons.org/licenses/ by-nc/4.0/) which permits others to copy and redistribute material just in noncommercial usages, provided the original work is properly cited. 
oxygen species (ROS) disrupting cell macromolecules involved in metabolic pathways $(5,6)$. Recently, tellurium has been applied in the development of novel materials such as fluorescent CdTe quantum dots (7, 8) and different telluride nanostructures (9), tellurium containing nanoparticles (NPs) (10), and tellurium nanotubes (11), which may find potential applications in the electronics and medicine as a new field of nanotechnology approaches.

Beside, the physicochemical approaches, such as, microwave-assisted synthesis, hydrothermal, and electrodeposition methods (12) developed for the production of the nanostructures, the biosynthesis of NPs has been introduced as a safe, clean, non-toxic, and environmental-friendly methods $(13,14)$. Some microorganisms such as Rhodobacter capsulatus (15), Acinetobacter haemolyticus (5), and Bacillus selenitireducens (16) have excellent capability in converting metalloid ions like tellurium into nanoparticles. In fact, these tellurite-resistant microbial strains introduce these metalloid oxyanions into their respiratory chain as electron acceptors where tellurium oxyanions are reduced to the metalloid $\mathrm{Te}^{0}(17)$. Reduction of the tellurite using nitrate reductases and other reductases present either in the periplasmic space or bound into outer membrane has been also introduced as another mechanism for the production of the elemental and insoluble form of Te which is then precipitated in the cell compartments $(6,17)$.

Although the antioxidant activity of some tellurium compounds like telluric hyaluronic acid has been previously confirmed (18), the literature review revealed no report on the antioxidant activity of the biogenic tellurium nanorods (Te NRs). Furthermore, the antimicrobial effect of Te NPs biosynthesized by some haloarchaeon bacteria such as Halococcus salifodinae was reported (19), but the combined effect of Te NPs and different antibiotics on the bacterial pathogens has not been determined yet.

\section{Objectives}

In the present study, the biogenic Te NRs produced by the Pseudomonas pseudoalcaligenes strain Te was purified and their antimicrobial activities, alone or in combination with different antibiotics, as well as their antioxidant effect were evaluated compared with those of potassium tellurite.

\section{Materials and Methods}

\subsection{Chemicals and Microorganisms}

Nutrient broth (NB), Muller-Hinton broth (MHB), Sabouraud dextrose broth (SDB), sodium dodecyl sulfate (SDS), n-octyl alcohol, 2,2-diphenyl1-picrylhydrazyl (DPPH), butylated hydroxyl toluene (BHT), 2,3,5-triphenyl-2H-tetrazolium chloride (TTC), sodium dihydrogen phosphate $\left(\mathrm{NaH}_{2} \mathrm{PO}_{4}\right)$, dibasic sodium phosphate $\left(\mathrm{Na}_{2} \mathrm{HPO}_{4}\right)$, potassium ferricyanide, trichloroacetic acid (TCA), ferric chloride $\left(\mathrm{FeCl}_{3}\right)$, potassium tellurite $\left(\mathrm{K}_{2} \mathrm{TeO}_{3}\right)$, and Tris- $\mathrm{HCl}$ were purchased from Merck Chemicals (Darmstadt, Germany). Standard antibiotic disks were purchased from Mast Company, UK. All the other chemicals and solvents were of the analytical grade.

The Te NPs-producing bacterial strain used in the present study was previously isolated from a spring (Kerman, Iran, $30^{\circ} 15 \mathrm{~N}, 56^{\circ} 58 \mathrm{E}$ ) and identified as Pseudomonas pseudoalcaligenes strain Te (20). The organism was constantly conserved on the nutrient agar plate containing $\mathrm{K}_{2} \mathrm{TeO}_{3}(2 \mathrm{mM})$ using continuous weekly sub-culturing. The following representative Gram-negative bacteria strains including E. coli (PTTC 1399), P. aeruginosa (PTTC 1574), and Salmonella typhi (PTCC 1609) were purchased from the Persian type culture collection (Iranian organizations for science and technology, IROST, Karaj, Iran). Furthermore, the clinical isolates of methicillin-resistant Staphylococcus aureus (MRSA), Candida albicans, and C. dubliniensis were used as the test organisms.

\subsection{Biosynthesis and Characterization of Te NRs}

Te NRs were biosynthesized using a newly described method (20). Briefly, sterile NB medium containing $\mathrm{K}_{2} \mathrm{TeO}_{3}$ (final concentration of $1 \mathrm{mM}$ ) was prepared. The medium $(100 \mathrm{~mL})$ was then inoculated with $1 \mathrm{~mL}$ of the fresh inoculums $\left(\mathrm{OD}_{600}, 0.1\right)$ of the $P$. pseudoalcaligenes strain Te and incubated aerobically in a shaker incubator $\left(30^{\circ} \mathrm{C}, 150 \mathrm{rpm}\right)$. After $80 \mathrm{~h}$, the bacterial cells were removed from the culture medium by centrifugation $(4,000 \times g, 10 \mathrm{~min})$ and the obtained pellet was washed using sterile $\mathrm{NaCl}$ solution $(0.9 \%)$ by centrifugation. The cells were consequently transferred to a mortar and were disrupted after grinding the frozen cells in the presence of liquid nitrogen. The resulting slurry was then ultrasonicated (100 W, $5 \mathrm{~min}$ ) and was washed three times using sequential centrifugation $(10,000 \times g, 5 \mathrm{~min})$ with $1.5 \mathrm{M}$ Tris- $\mathrm{HCl}$ buffer $(\mathrm{pH} 8.3)$ containing 1\% SDS and deionized water, respectively. Subsequently, Te NRs were extracted and were purified using an organic-aqueous two-phase partitioning system (n-octyl alcohol-water) as described earlier (20). For transmission electron microscopy (TEM), the Te NRs were dispersed ultrasonically and a drop of the suspension was placed on carbon-coated copper TEM grids and dried under an IR lamp. Micrographs were 
then obtained using a TEM (Zeiss 902A) apparatus coupled with an energy dispersive X-ray (EDX) microanalyzer operated at the accelerating voltage of $80 \mathrm{kV}$. The related size distribution pattern of the Te NPs was plotted by the manual counting of the 300 individual particles from different TEM images.

\subsection{Evaluating the Antimicrobial Effects}

\subsubsection{Microdilution Method}

The conventional microplate method was used to determine the minimal inhibitory concentration (MIC) of Te NRs and $\mathrm{K}_{2} \mathrm{TeO}_{3}$ with some modification (21). Briefly, sterile MHB was supplemented with different concentrations of Te NRs (0.25-4 mg. $\left.\mathrm{mL}^{-1}\right)$ and $\mathrm{K}_{2} \mathrm{TeO}_{3}$ $\left(0.125-8 \mu \mathrm{g} \cdot \mathrm{mL}^{-1}\right)$. The 96-well round-bottom sterile microplates were then separately filled with $180 \mu \mathrm{L}$ of the above mixtures and $20 \mu \mathrm{L}$ of the freshly prepared bacterial pathogens including E. coli, $P$. aeruginosa, $S$. typhi, and MRSA to obtain the final inoculums of $10^{5}$ CFU.mL ${ }^{-1}$ were added into each well and incubated overnight at $37^{\circ} \mathrm{C}$. Thereafter, $20 \mu \mathrm{L}$ of the sterile TTC solution $\left(0.5 \mathrm{mg} . \mathrm{mL}^{-1}\right)$ was added to each well and incubated for an additional $2 \mathrm{~h}$. MIC was expressed as the lowest concentration of the samples at which no visible red color (due to the reduction of tetrazolium indicator into the related formazan) was observed. The antibiotic ciprofloxacin (Sigma-Aldrich, St. Louis, MO, USA) was included in each assay as the positive control, while sterile MHB was applied as a negative control. For the clinical isolates of the $C$. albicans and C. dubliniensis, the aforementioned concentrations of the Te NRs and $\mathrm{K}_{2} \mathrm{TeO}_{3}$ were prepared in SDB medium and after exposure time $\left(30^{\circ} \mathrm{C}, 24 \mathrm{~h}\right)$, the growth was detected by culturing from each well onto the plates containing Sabouraud dextrose agar. The antibiotic fluconazole (Sigma-Aldrich, St. Louis, MO, USA) was included in each assay as the positive control, while the sterile SDB was used as a negative control. All the experiments were repeated three times on different days and their means were reported.

\subsubsection{Disk Diffusion Assay}

Disk diffusion susceptibility test was carried out on MHA plates in order to examine the antibacterial activity of the Te NRs, $\mathrm{K}_{2} \mathrm{TeO}_{3}$, and candidate antibiotics against the clinical isolate of MRSA. A single colony of MRSA was grown overnight in MHB medium in a shaker incubator $\left(37^{\circ} \mathrm{C}, 150 \mathrm{rpm}\right)$ and the obtained culture

Table 1. The antibacterial activity of antibiotics alone and in combination with $\mathrm{K}_{2} \mathrm{TeO}_{3}$ or Te NRs against MRSA.

\begin{tabular}{|c|c|c|c|}
\hline \multicolumn{4}{|c|}{ Mean of inhibition Zone (mm) } \\
\hline $\begin{array}{c}\text { Antibiotics } \\
(\mu \mathrm{g} / \text { disk })\end{array}$ & $\begin{array}{c}\text { Antibiotic } \\
\text { alone }\end{array}$ & $\begin{array}{c}\text { Antibiotic plus } \mathrm{K}_{2} \mathrm{TeO}_{3} \\
(0.25 \mathrm{mg} / \text { disk })\end{array}$ & $\begin{array}{c}\text { Antibiotic plus Te NRs } \\
(2 \mathrm{mg} / \text { disk })\end{array}$ \\
\hline CLX (5) & 0 & $13.3 \pm 3.5$ & 0 \\
\hline TOB (10) & $8.3 \pm 0.6$ & $9.6 \pm 1.1$ & 0 \\
\hline NA (30) & 0 & $17 \pm 1$ & 0 \\
\hline CRF (30) & 0 & $16.6 \pm 1.1$ & 0 \\
\hline $\mathrm{BA}(0.04)$ & 0 & 0 & 0 \\
\hline CPR (5) & 0 & $10.6 \pm 2$ & 0 \\
\hline $\mathrm{E}(15)$ & 0 & $15.6 \pm 1.5$ & 0 \\
\hline ME (5) & 0 & $12.3 \pm 4$ & 0 \\
\hline VAN (30) & $23 \pm 2.6$ & $18.6 \pm 1.1$ & 0 \\
\hline CEX (30) & 0 & $20.3 \pm 1.5$ & 0 \\
\hline CFM (5) & 0 & $15.6 \pm 3$ & 0 \\
\hline GM (10) & $19.3 \pm 1.5$ & $24 \pm 1.7$ & 0 \\
\hline $\operatorname{IMP}(10)$ & 0 & $11.6 \pm 0.5$ & 0 \\
\hline TE (30) & $24.6 \pm 1.5$ & $25 \pm 1$ & 0 \\
\hline AMK (30) & $12.6 \pm 0.6$ & $14.3 \pm 2$ & 0 \\
\hline STR (10) & $8.6 \pm 0.6$ & $14.6 \pm 0.5$ & 0 \\
\hline KAN (30) & $11 \pm 1$ & $12.3 \pm 1.5$ & 0 \\
\hline
\end{tabular}

CLX (Cloxacillin), TOB (Tobramycin), NA (Nalidixic acid), CRF (Ceftriaxone), BA (Bacitracin), CPR (Ciprofloxacin), E (Erythromycin), ME (Methicillin), VAN (Vancomycin), CEX (Cephalexin), CFM (Cefixime), GM (Gentamicin), IMP (Imipenem), TE (Tetracycline), AMK (Amikacin), STR (Streptomycin), KAN (Kanamycin). 
was diluted to obtain the $0.5 \mathrm{McFarland}$ standard with sterile normal saline followed by its application onto the surface of MHA plates using a swab to ensure the uniform distribution of MRSA. The standard antibiotic disks (Table 1), blank disks containing only Te NRs, or different concentration of $\mathrm{K}_{2} \mathrm{TeO}_{3}$ (i.e., $0.031,0.062,0.125,0.25,0.5,1$, and $2 \mathrm{mg} /$ disk), and antibiotic discs loaded with Te NRs $\left(2 \mathrm{mg} \cdot \mathrm{mL}^{-1}\right)$ or $\mathrm{K}_{2} \mathrm{TeO}_{3}\left(0.25 \mathrm{mg} \cdot \mathrm{mL}^{-1}\right)$ were then separately overlaid on the surface of the inoculated media followed by the overnight incubation at $37{ }^{\circ} \mathrm{C}$ and the inhibition zones were measured. The above-mentioned disk diffusion method was performed in triplicate and the mean of the measured inhibition zones was measured.

\subsection{Antioxidant Assay}

\subsubsection{DPPH Scavenging Activity}

DPPH scavenging activity was investigated using the method previously described with some modifications (22). One milliliter of the Te $\mathrm{NRs}$ or $\mathrm{K}_{2} \mathrm{TeO}_{3}$ at different concentrations (10-500 $\left.\mu \mathrm{g} \cdot \mathrm{mL}^{-1}\right)$ was mixed with $1 \mathrm{~mL}$ of the freshly prepared DPPH solution in the methanol $(0.15 \mathrm{mM})$. Subsequently, methanol $(3 \mathrm{~mL})$ was added, the prepared mixture was maintained at room temperature in the dark for $30 \mathrm{~min}$, and the absorbance was measured at $517 \mathrm{~nm}$ using a UV-visible double beam PC scanning spectrophotometer (UV-1800, Shimadzu CO, USA) (18). The negative control was designed by replacing the Te NRs or $\mathrm{K}_{2} \mathrm{TeO}_{3}$ stocks with deionized water. This experiment was also repeated for BHT as the positive controls at the same concentration. The percentage of DPPH scavenging activity was calculated as follow:

DPPH radical scavenging activity $(\%)=\left[1-\left(\mathrm{A}_{\mathrm{a}}-\mathrm{A}_{\mathrm{b}}\right) /\right.$ $\left.\mathrm{A}_{\mathrm{c}}\right] \times 100$

Where $A_{a}$ is the absorbance of the sample mixed with DPPH solution, $A_{b}$ is the absorbance of the sample without DPPH solution, and $\mathrm{A}_{\mathrm{c}}$ is the absorbance of the negative control solution. The required concentration for inhibiting $50 \%$ of DPPH $\left(\mathrm{IC}_{50}\right)$ was then calculated by linear regression. Three independent replicates of the above-mentioned experiments were carried out and the mean of the obtained results was reported.

\subsubsection{Reducing Power Assay}

The reducing power of the Te NRs and $\mathrm{K}_{2} \mathrm{TeO}_{3}$ was determined by applying the adapted method of Oyaizu (23). Briefly, $1 \mathrm{~mL}$ from different concentrations of Te NRs or $\mathrm{K}_{2} \mathrm{TeO}_{3}\left(10-1000 \mu \mathrm{g} \cdot \mathrm{mL}^{-1}\right)$ was mixed with 0.5 $\mathrm{mL}$ of sodium phosphate buffer $(0.2 \mathrm{M}, \mathrm{pH} 6.6)$ and 0.5
$\mathrm{mL}$ of potassium ferricyanide $(30 \mathrm{mM})$ and the prepared mixture was incubated in a water bath $\left(50{ }^{\circ} \mathrm{C}, 20 \mathrm{~min}\right)$. Thereafter, $2 \mathrm{~mL}$ of TCA solution $(0.6 \mathrm{M})$ was added and the mixture was centrifuged $(4,000 \times g, 10 \mathrm{~min})$. Afterwards, $0.5 \mathrm{~mL}$ of the obtained supernatant was mixed with the deionized water $(0.5 \mathrm{~mL})$ in addition to $0.1 \mathrm{~mL}$ of $\mathrm{FeCl}_{3}$ solution $(6 \mathrm{mM})$ and the absorbance at $700 \mathrm{~nm}$ was recorded. The blank was prepared by replacing Te NRs or $\mathrm{K}_{2} \mathrm{TeO}_{3}$ solution with deionized water. Similar experiments were repeated for BHT as the reference compound at the same concentration. These procedures were repeated three times on various days and the mean of the absorbance was employed to draw an appropriate curve.

\subsection{Statistical Analysis}

The software SPSS 15 for Windows (SPSS Inc., Chicago) was used for the statistical analysis and the differences between the groups were determined using one-way analysis of variance (ANOVA). The $p$-values of less than 0.05 were considered as significant.

\section{Results}

\subsection{Production, Purification, and Characterization of Te NRs}

The culture medium of P. pseudoalcaligenes strain Te exhibited a gradual change of the color toward black during $80 \mathrm{~h}$ incubation in the presence of $\mathrm{K}_{2} \mathrm{TeO}_{3}(1$ $\mathrm{mM}$ ) which indicated the reduction of $\mathrm{Te}^{+4}$ ions to $\mathrm{Te}^{0}$ nanoparticles (Fig. 1a). In order to confirm the probable pigment production which interferes with the tellurium ion reduction, similar cultivation in absence of $\mathrm{Te}^{+4}$ ions was performed. The obtained results (Fig. 1b) indicate that production of Te nanostructure; and not the pigment production, is responsible for such a color change. The applied three-phase partitioning system, as previously was used for the purification of biogenic Te NPs and Se NPs $(20,22)$ through the application of $n$-octanol, made us able to purify the biologically synthesized Te NRs in the present study. This was evident in Figure 2a, which shows the TEM image of the biogenic Te NRs,

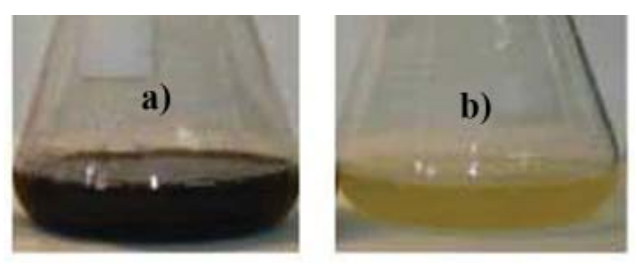

Figure 1. Cultivation of $P$. pseudoalcaligenes strain Te in the; a) presence and b) absence of the $\mathrm{Te}^{+4}$ ions. 


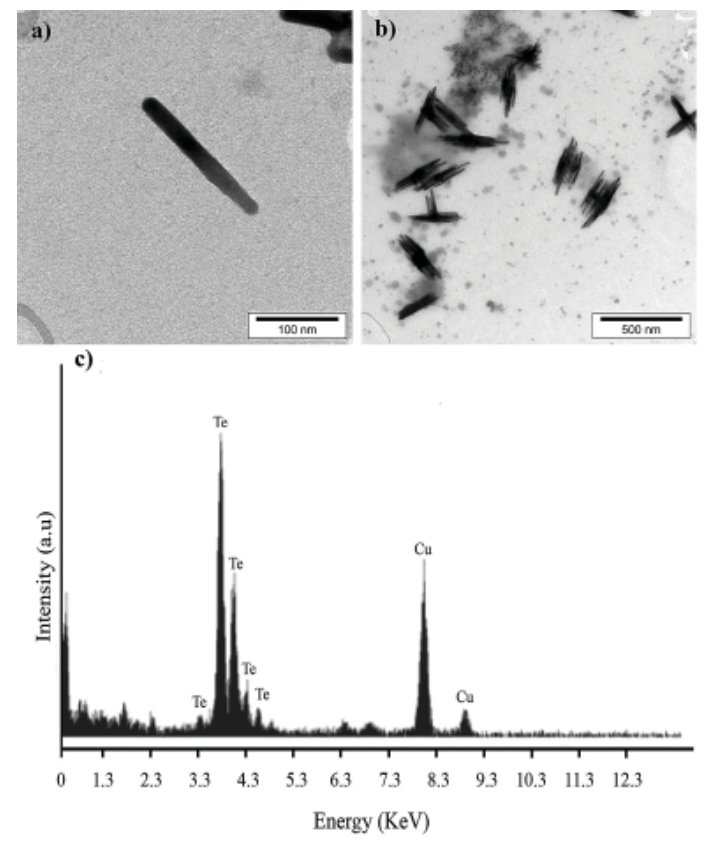

Figure 2. The transmission electron microscopy (TEM) image of the Te NRs (a) Te NRs rosettes (b), and the energy dispersive X-ray spectrum of the Te NRs (c) biosynthesized by $P$. pseudoalcaligenes strain Te.

representing rod-shape nanostructures with $185 \mathrm{~nm}$ in length by the less than $20 \mathrm{~nm}$ of the width $(185 \mathrm{~nm}$ X 20 $\mathrm{nm}$ ). Furthermore, larger rosettes composed of several Te NRs were observed (Fig. 2b). The occurrence of such rosettes in culture media of other tellurium resistant bacterial strains such as $B$. selenitireducens was previously reported to be due to the adherence of Te NRs to each other through electrostatic interaction (16). Furthermore, microanalysis of the purified Te NRs using EDX method represented the Te absorption peak at $3.72 \mathrm{keV}$ (Fig. 2c) and the $\mathrm{Cu}$ peaks which originated from the TEM copper grid. The corresponding size distribution patterns of Te NRs measured from the manual counting of 300 individual particles from different TEM images has revealed that the nanoparticles were in the size range of 50-200 nm and the most frequent particles were in size range of 75-100 nm (Fig. 3).

Recently, Borghese et al. (17) have reported that the oxyanion of tellurite transformed into needle-like black Te NPs with the size range of 200-800 nm after 10 days of anaerobic incubation in the presence of $R$. capsulatus. Among the 123 tellurite-resistant bacteria isolated from the extreme environment of Antarctica, six Te NPs-producing strains (i.e., Staphylococcus, Acinetobacter, and Pseudomonas genus) were obtained which displayed about 35-500 fold resistance to tellurite compared to that of the tellurium-sensitive E. coli (5).

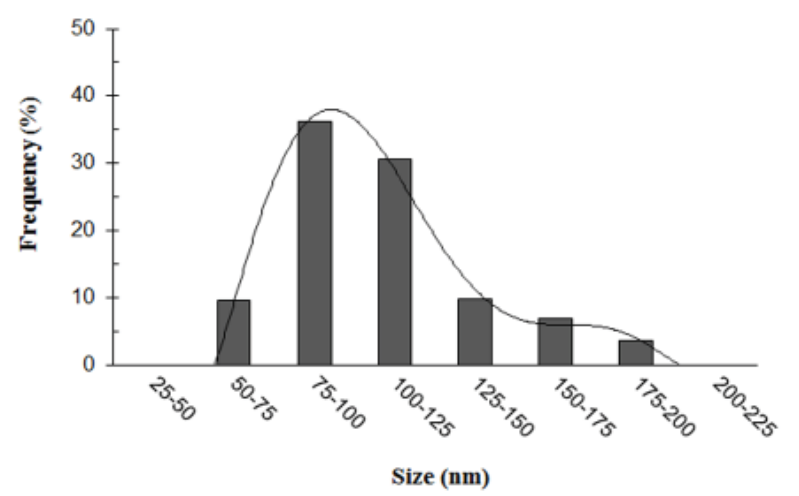

Figure 3. The particle size distribution pattern of the Te NRs as obtained by the manual counting of the 300 individual particles from different TEM images.

\subsection{Antimicrobial Activity of the Te NRs}

The serial dilution method was used to determine the MICs of the Te NRs and $\mathrm{K}_{2} \mathrm{TeO}_{3}$ against different microbial pathogens. For E. coli, $P$. aeruginosa, $S$. typhi, MRSA, C. albicans, and C. dubliniensis treated with Te NRs, the MIC was found to be $1 \mathrm{mg} \cdot \mathrm{mL}^{-1}, 1$ mg.mL ${ }^{-1}, 4$ mg.mL ${ }^{-1}, 2$ mg.mL $L^{-1},<4$ mg. $\mathrm{mL}^{-1}$ and $<4$ $\mathrm{mg} \cdot \mathrm{mL}^{-1}$, respectively. However, in case of potassium tellurite MIC was determined to be $0.125 \mu \mathrm{g} \cdot \mathrm{mL}^{-1}, 16$ $\mu \mathrm{g} \cdot \mathrm{mL}^{-1}, 0.5 \mu \mathrm{g} \cdot \mathrm{mL}^{-1}, 32 \mu \mathrm{g} \cdot \mathrm{mL}^{-1}, 1024 \mu \mathrm{g} \cdot \mathrm{mL}^{-1}$, and $512 \mu \mathrm{g} . \mathrm{mL}^{-1}$ for E. coli, P. aeruginosa, S. typhi, MRSA, C. albicans, and C. dubliniensis, respectively. For all tested bacteria treated with ciprofloxacin the MIC, was found to be $<0.05 \mu \mathrm{g} \cdot \mathrm{mL}^{-1}$. As well, for C. albicans and C. dubliniensis treated with fluconazole, the MIC was found to be $1024 \mu \mathrm{g} \cdot \mathrm{mL}^{-1}$ and $512 \mu \mathrm{g} \cdot \mathrm{mL}^{-1}$, respectively. In this study, the antibacterial activity of the different antibiotics alone or in combination with a sub-inhibitory amount of Te NRs ( $2 \mathrm{mg} /$ disk $)$ or $\mathrm{K}_{2} \mathrm{TeO}_{3}(0.25 \mathrm{mg} /$ disk $)$ were also investigated by disk diffusion method against the clinical isolate of the MRSA. The disks containing only the sub-MIC amount of the Te NRs $(0.031 \mathrm{mg} /$ disk to $2 \mathrm{mg}$ /disk) did not exhibit any inhibition zones against the MRSA (Table 1). The measured inhibition zones for the disks containing $0.5 \mathrm{mg}, 1 \mathrm{mg}$, and 2 $\mathrm{mg}$ of $\mathrm{K}_{2} \mathrm{TeO}_{3}$ were $10.5 \mathrm{~mm}, 13.3 \mathrm{~mm}$, and $16.7 \mathrm{~mm}$, respectively (Table 1). For other disks containing 0.031 $\mathrm{mg}, 0.062 \mathrm{mg}, 0.125 \mathrm{mg}$, and $0.25 \mathrm{mg}$ of $\mathrm{K}_{2} \mathrm{TeO}_{3}$ not a zone of inhibition was determined (Table 1). Among the tested antibiotics, only tobramycin, vancomycin, gentamicin, tetracycline, amikacin, streptomycin, and kanamycin were shown the antibacterial effects against the tested MRSA (Table 1).

For antibiotic disks containing $\mathrm{K}_{2} \mathrm{TeO}_{3}$, it seems that the presence of potassium tellurite has significantly increased the antibacterial effect of vancomycin, 


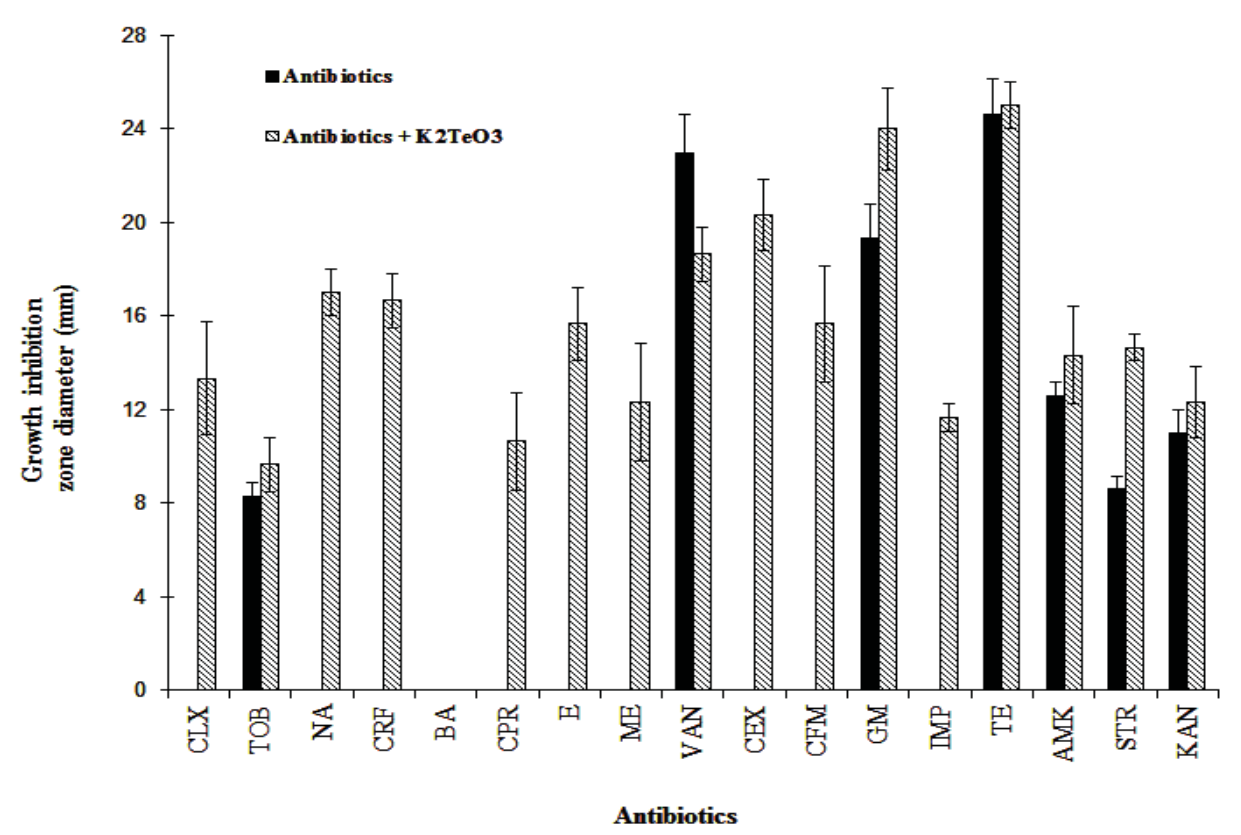

Figure 4. The antibacterial effect of the different antibiotics in combination with $\mathrm{K}_{2} \mathrm{TeO}_{3}$ against MRSA.

gentamicin, and streptomycin against the tested MRSA $(p<0.05)$ (Fig. 4). Furthermore, $\mathrm{K}_{2} \mathrm{TeO}_{3}$ showed an antibacterial effect in combination with all the tested antibiotics except bacitracin against the tested MRSA (Fig. 4).

\subsection{Antioxidant Properties}

DPPH radical-scavenging activity of the Te NRs and $\mathrm{K}_{2} \mathrm{TeO}_{3}$ through DPPH are illustrated in Figure 5a. As shown in all tested concentration of BHT the scavenging activity was significantly higher than the Te NRs and $\mathrm{K}_{2} \mathrm{TeO}_{3}\left(p<0.05\right.$, Fig. 5a). The $\mathrm{IC}_{50}$ values of the $\mathrm{BHT}$ and biogenic Te NRs were found to be $12.45 \mu \mathrm{g} \cdot \mathrm{mL}^{-1}$ and $24.9 \mu \mathrm{g} . \mathrm{mL}^{-1}$, respectively. However, in the case of



$\mathrm{K}_{2} \mathrm{TeO}_{3}$ only $17.6 \pm 0.8 \%$ scavenging effect was observed at $160 \mu \mathrm{g} \cdot \mathrm{mL}^{-1}$ of the concentration. By increasing the Te NRs concentration to $320 \mu \mathrm{g} \cdot \mathrm{mL}^{-1}$ and $640 \mu \mathrm{g} \cdot \mathrm{mL}^{-1}$, the scavenging effect hasn't significantly increased when compared to the concentration of $160 \mu \mathrm{g} \cdot \mathrm{mL}^{-1}(p>$ 0.05 ) (data not shown). The reduction of Fe (III) ions is regularly used as an indicator of electron-donating power (22). The reducing power of Te NRs, $\mathrm{K}_{2} \mathrm{TeO}_{3}$ and $\mathrm{BHT}$ at different concentrations is shown in the Figure 5b. At the concentrations above $80 \mu \mathrm{g} \cdot \mathrm{mL}^{-1}$, the reducing power of the Te NRs and $\mathrm{K}_{2} \mathrm{TeO}_{3}$ was significantly lower than BHT $(p<0.05)$. Moreover, the reducing power of Te NRs at the same concentration above the $320 \mu \mathrm{g} \cdot \mathrm{mL}^{-1}$ was significantly higher than the $\mathrm{K}_{2} \mathrm{TeO}_{3}(p<0.05)$.

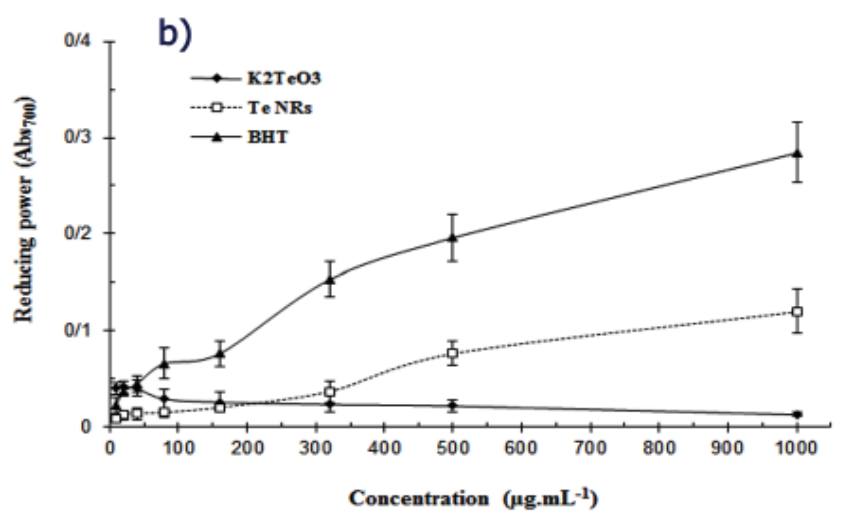

Figure 5. a) The scavenging effects and b) the reducing power of biogenic $\mathrm{Te} \mathrm{NRs}$ and $\mathrm{K}_{2} \mathrm{TeO}_{3}$ in comparison to the BHT as a standard control. Each value is represented as the mean $\pm \mathrm{SD}$ of the three independent experiments. 


\section{Discussion}

In general, for the examined bacterial and fungal strains evaluated in the present study, the biogenic Te NRs represented lower a toxicity compared to that of $\mathrm{K}_{2} \mathrm{TeO}_{3}(\mathrm{p}<0.05)$. Reviewing literature has revealed that following the microbial reduction of $\mathrm{K}_{2} \mathrm{TeO}_{3}$ and other chalcogen oxyanions such as sodium selenite, the toxicity of the produced nanostructures will decrease. For example, in the study of Forootanfar et al. (20), the cytotoxic activity of the biogenic Te NPs on four cell lines including A549, HepG2, HT1080, and MCF-7 was evaluated and a higher $\mathrm{IC}_{50}$ value was found for Te NRs compared to $\mathrm{TiO}_{3}^{2-}$. Zare et al. (24) have investigated the antibacterial effect of Te NRs $(180 \mathrm{~nm} \times 20 \mathrm{~nm})$ produced by the Bacillus sp. BZ against Staphylococcus aureus (MIC $250 \mu \mathrm{g} . \mathrm{mL}^{-1}$ ), P. aeruginosa (MIC 125 $\mu \mathrm{g} . \mathrm{mL}^{-1}$ ), S. typhi (MIC $125 \mu \mathrm{g} . \mathrm{mL}^{-1}$ ), and K. pneumonia (MIC $125 \mu \mathrm{g} \cdot \mathrm{mL}^{-1}$ ). Furthermore, they reported the presence of different functional group on the surface of Te NRs is related to the different compounds bound to the surface during the reduction process. Although, the Te NRs prepared by $P$. pseudoalcaligenes strain Te in the present study exhibited approximately the same size range with the produced Te NRs by Bacillus sp. BZ but they did not show any typical functional groups (20). It seems that the presence of such functional groups explain the lower MIC values of Te NRs produced by Bacillus sp. BZ in comparison to Te NRs prepared by P. pseudoalcaligenes strain Te. In another study, Zare et al. (25) have reported that the Te NRs can completely inhibit the growth of $C$. albicans at concentrations of $\geq 2000 \mu \mathrm{g} \cdot \mathrm{mL}^{-1}$ through inhibition of the squalene monooxygenase gene expression. In addition, Lin et al. (26) reported that different Te nanomaterials such as nanowires $(20 \mathrm{~nm}$ diameter by $880 \mathrm{~nm}$ length), nanopencils $(70 \mathrm{~nm}$ diameter by $440 \mathrm{~nm}$ length), nanorices $(50 \mathrm{~nm}$ diameter by $130 \mathrm{~nm}$ length), and nanocubes $(80 \mathrm{~nm})$ which were prepared by the chemical reduction of tellurium dioxide by hydrazine represented a higher antibacterial activity against $E$. coli compared to Ag nanoparticles that are commonly used as antibacterial reagents. They also reported that the antibacterial effect of nanocubes and nanorices are approximately equal and their antibacterial effect is higher than nanopencils and nanowires (26). It seems that the higher size of $\mathrm{Te}$ nanomaterials, the lower antibacterial activity could be observed (26).

The use of antibiotics in combination with different compounds is an approach to overcome the problem of antibiotics resistance (27). Enhancing the antibacterial effect of the different antibiotics used in combination with silver or zinc oxide nanoparticles were previously reported $(28,29)$. In the present investigation, the disks containing antibiotics and Te NRs ( $2 \mathrm{mg} / \mathrm{disk})$ did not show any antibacterial activity (Table 1). Thus, the Te NRs not only did not represent antibacterial effect against the tested MRSA but also inhibit the antibacterial activity of effective antibiotics in disk diffusion method. This might be ascribed to the solubility problem of the Te NRs which need for diffusion of this nanostructure through the culture media and exhibition of antibacterial effect. Molina-Quiroz et al. (30) have reported that potassium tellurite, which is more soluble than $\mathrm{Te}$ NPs and cefotaxime acted synergistically in sub-lethal concentrations against $E$. coli and the tellurite-mediated antibiotic-potentiating effect occurred especially with antibiotics disrupting the cell wall (such as ampicillin and cefotaxime) or protein synthesis (like tetracycline, chloramphenicol, and gentamicin). Adsorption of the antibiotics to the surface of Te NRs (due to their large surface-to-volume ratio) and as a result decreasing the diffusion efficiency might be another probable reason for such observation.

Results obtained through investigation on the antioxidant potentials of the Te NRs showed that at all the applied concentrations the percentage of radical scavenging for the Te NRs was significantly higher than $\mathrm{K}_{2} \mathrm{TeO}_{3}(\mathrm{p}<0.05)$ (Fig. 5a). This effect might be attributed to the large surface area provided by the Te NRs which can easily react with DPPH radicals. Yunzhi et al. (31) reported that Te NPs $(70 \mathrm{~nm}$ in width and $500 \mathrm{~nm}$ in length) prepared by the reduction of sodium tellurite using ascorbic acid in the sucrose solution were the dominating contributors to the radical scavenging activity of the Te NPs-sucrose solution and the antioxidant activity of insoluble Te NPs was higher than soluble sodium tellurite. It has been reported that tellurite toxicity results from its capacity to act as a strong oxidizing agent over a variety of cell components (32) and tellurite could exert its toxicity through intracellular compartment by the generation of reactive oxygen species (ROS) (33). Forootanfar et al. (22) have reported that other chalcogens such as $\mathrm{Se}^{+4}$ ions which are soluble in aqueous media bestow a higher electrondonating activity than insoluble Se NPs. However, based on the obtained results of the present study it seems that in a concentration above $320 \mu \mathrm{g} \cdot \mathrm{mL}^{-1}$ the reducing power of soluble $\mathrm{K}_{2} \mathrm{TeO}_{3}$ is significantly lower than insoluble biogenic Te NRs $(p<0.05)$ (Fig. $5 b)$.

\section{Conclusions}

The obtained data for DPPH radical scavenging activity showed that antioxidant activity of the biogenic $\mathrm{Te}$ NRs (produced by P. pseudoalcaligenes strain Te) is 
significantly higher than $\mathrm{K}_{2} \mathrm{TeO}_{3}$. Furthermore, the reducing power of Te NRs was significantly higher than $\mathrm{K}_{2} \mathrm{TeO}_{3}$ at the concentration above $320 \mu \mathrm{g} \cdot \mathrm{mL}^{-1}$. Based on the data obtained from both microdilution and disk diffusion method the $\mathrm{K}_{2} \mathrm{TeO}_{3}$ exhibited a higher antimicrobial and antifungal activity than Te NRs. Te NRs didn't show an antibacterial effect against the tested MRSA and they inhibited the antibacterial activity of the effective antibiotics. However, further investigations are required in order to reveal the mechanism of action of the produced biogenic Te NRs.

\section{Acknowledgments}

This work was financially supported by grant number 94/387 from Deputy of Research, Kerman University of Medical Sciences (Kerman, Iran). We thank the Herbal and Traditional Medicines Research Center, Kerman University of Medical Sciences (Kerman, Iran) and Iranian Nanotechnology Initiative Council for their admirable participation in this study.

\section{References}

1. MohantyA, Liu Y, Yang L, Cao B. Extracellular biogenic nanomaterials inhibit pyoverdine production in Pseudomonas aeruginosa: a novel insight into impacts of metal(loid) $\mathrm{s}$ on environmental bacteria. Appl Microbiol Biotechnol. 2015;99(4):1957-1966. DOI: 10.1007/s00253-014-6097-5

2. Ba LA, Doring M, Jamier V, Claus Jacob C. Tellurium: an element with great biological potency and potential. Org Biomol Chem. 2010;8(19):4203-4216. DOI: 10.1039/c0Ob00086h

3. Cunha RLOR, Gouvea IE, Juliano L. A glimpse on biological activities of tellurium compounds. An Acad Bras Ciênc. 2009;81(3):393-407. DOI: 10.1590/S000137652009000300006

4. Turner RJ, Borghese R, Zannoni D. Microbial processing of tellurium as a tool in biotechnology. Biotechnol Adv. 2012;30(5):954-963. DOI: 10.1016/j.biothechadv.2011.08018

5. Arenas FA, Pugin B, Henri'quez NA, Arenas-Salinas MA, D1'az-Va'squez WA, Pozo MF, Muñoz CA, Chasteen TG, Pe'rez-Donoso JM, Va'squez CC. Isolation, identification and characterization of highly telluriteresistant, telluritereducing bacteria from Antarctica. Polar Sci. 2014;8:40-52. DOI:10.1016/j.polar.2014.01.001

6. Narayanan KB, Sakthivel N. Biological synthesis of metal nanoparticles by microbes. Adv Colloid Interface Sci. 2010;156:1-13. DOI:10.1016/j.cis.2010.02.001

7. Rodrigues DMC, Ribeiro DSM, Frigerio C, Rodrigues SSM, Santos JLM, Prior JAV. Antioxidant capacity automatic assay based on inline photogenerated radical species from L-glutathione-capped CdTe quantum dots. Talanta. 2015;141:220-229. DOI:10.1016/j.talanta.2015.04.013

8. Fei X, Sun W, Cao L, Jiao X, Lin D, Jia G. Design and preparation of quantum dots fluorescent probes for in situ identification of Microthrix parvicella in bulking sludge. Appl Microbiol Biotechnol. 2015;100(2):961-968. DOI: 10.1007/ s00253-015-7015-1

9. Kim C, Kim DH, Han YS, Chung JS, Park SH, Park S, Kim
H. Development of bismuth tellurium selenide nanoparticles for thermoelectric applications via a chemical synthetic process. Mat Res Bull. 2011;46(3):407-412. DOI: 10.1016/j. materresbull.2010.12.004

10. Wan B, Hu C, Liu H, Xiong Y, Li F, Xi Y, He X. Growth of $\mathrm{PbTe}$ nanorods controlled by polymerized tellurium anions and metal (II) amides via composite-hydroxide-mediated approach. Mat Res Bull. 2009;44(9):846-1849. DOI: DOI: 10.1016/j. materresbull.2009.05.016

11. Xi G, Peng Y, Yu W, Qian Y. Synthesis, characterization, and growth mechanism of tellurium nanotubes. Cryst Growth Des. 2005;5(1):325-328. DOI: 10.1021/cg049867p

12. Panahi-Kalamuei M, Mousavi-Kamazani M, Salavati-Niasari M. Self-assembly of nanoparticles to form tree-like tellurium nanostructures using novel starting reagents. Mater Lett. 2014;136:218-221. DOI:10.1016/j.matlet.2014.08.069

13. Bhattacharya D, Gupta RK. Nanothechnology and potential of microorganisms. Crit Rev Biotechnol. 2005;25(4):199-204. DOI:10.1080/07388550500361994

14. Park TJ, Lee KG, Lee SY. Advances in microbial biosynthesis of metal nanoparticles. Appl Microbiol Biotechnol. 2016;100(2):521-534. DOI:10.1007/s00253-015-6904-7

15. Borsetti F, Borghese R, Francia F, Randi MR, Fedi S, Zannoni D. Reduction of potassium tellurite to elemental tellurium and its effect on the plasma membrane redox components of the facultative phototroph Rhodobacter capsulatus. Protoplasma. 2003;221(1-2):152-161.

16. Baesman SM, Bullen TD, Dewald J, Zhang D, Curran S, Islam FS, Beveridge TJ, Oremland RS. Formation of tellurium nanocrystals during anaerobic growth of bacteria that use Te oxyanions as respiratory electron acceptors. Appl Environ Microbiol. 2007;73(3):2135-2143. DOI: 10.1128/AEM.0255806

17. Borghese R, Brucale M, Fortunato G, Lanzi M, Mezzi A, Valle F, Cavallini M, Zannoni D. Extracellular production of tellurium nanoparticles by the photosynthetic bacterium Rhodobacter capsulatus. J Hazard Mater 2016;309:202-209.DOI: 10.1016/j. jhazmat.2016.02.011

18. Chen Z, Lv J, Chen F, Lin L. Studies on telluric hyaluronic acid (TeHA): A novel antioxidant. J Mol Catal B. 2008;55(3-4):99103. DOI:10.1016/j.molcatb.2008.02.003

19. Srivastava P, Nikhil EVR, Bragança JM, Kowshik M. Anti-bacterial Te NPs biosynthesized by haloarcheaon Halococcus salifodinae BK3. Extremophiles. 2015;19(4):875884. DOI: $10.1007 / \mathrm{s} 00792-015-0767-9$

20. Forootanfar H, Amirpour-Rostami S, Jafari M, Forootanfar A, Yousefizadeh Z, Shakibaie M. Microbial-assisted synthesis and evaluation the cytotoxic effect of tellurium nanorods. Mater Sci Eng C. 2015;49:183-189. DOI: 10.1016/j.msec.2014.12.078

21. Eloff JN. A sensitive and quick microplate method to determine the minimal inhibitory concentration of plant extracts for bacteria. Planta Med. 1998;64(8):711-713. DOI: 10.1055/s2006-957563

22. Forootanfar H, Adeli-Sardou M, Nikkhoo M, Mehrabani M, Amir-Heidari B, Shahverdi AR, Shakibaie M. Antioxidant and cytotoxic effect of biologically synthesized selenium nanoparticles in comparison to selenium dioxide. J Trace Elem Med Biol. 2014;28(1):75-79. DOI: 10.1016/j.jtemb.2013.07.005

23. Oyaizu M. Studies on products of browning reactions: antioxidative activities of products of browning reaction prepared from glucosamine. Jpn J Nutr.1986;44:307-315. DOI: 
10.5264/eiyogakuzashi.44.307

24. Zare B, Faramarzi MA, Sepehrizadeh Z, Shakibaie M, Rezaie $\mathrm{S}$, Shahverdi AR. Biosynthesis and recovery of rod-shaped tellurium nanoparticles and their bactericidal activities. Mater Res Bull. 2012;47(11):3719-3725. DOI:10.1016/j. materresbull.2012.06.034

25. Zare B, Sepehrizadeh Z, Faramarzi MA, Soltany-Rezaeerad M, Rezaie S, Shahverdi AR. Antifungal activity of biogenic tellurium nanoparticles against Candida albicans and its effects on the squalene monooxygenase gene expression. Biotechnol Appl Biochem. 2014;61(4):395-400. DOI: 10.1002/bab.1180

26. Lin Z-H, Lee C-H, Chang H-Y, Chang H-T. Antibacterial activities of tellurium nanomaterials. Chem Asian J. 2012;7(5):930-934. DOI: 10.1002/asia.201101006.

27. Esmail Nazari Z, Banoee M, Akhavan Sepahi A, Rafii F, Shahverdi AR. The combination effects of trivalent gold ions and gold nanoparticles with different antibiotics against resistant Pseudomonas aeruginosa. Gold Bull. 2012;45(2):53-59. DOI: 10.1007/s13404-012-0048-7

28. Shahverdi AR, Fakhimi A, Shahverdi HR, Minaian S. Synthesis and effect of silver nanoparticles on the antibacterial activity of different antibiotics against Staphylococcus aureus and Escherichia coli. Nanomedicine. 2007;3(2):168-171. DOI:10.1016/j.nano.2007.02.001

29. Banoee M, Seif S, Esmail Nazari Z, Jafari-Fesharaki P,
Shahverdi HR, Moballegh A, Moghaddam KM, Shahverdi AR. ZnO nanoparticles enhanced antibacterial activity of ciprofloxacin against Staphylococcus aureus and Escherichia coli. J Biomed Matter Res B. Appl Biomater. 2010;93B(2):557561. DOI: $10.1002 / \mathrm{jbm} . b .31615$

30. Molina-Quiroz RC, Muñoz-Villagrán $\mathrm{CM}$, de la Torre E, Tantaleán JC, Vásquez CC, Pérez-Donoso JM. Enhancing the antibiotic antibacterial effect by sub lethal tellurite concentrations: Tellurite and cefotaxime act synergistically in Escherichia coli. Plos One 2012;7(4):1-6. DOI: 10.1371/ journal.pone.0035452

31. Yunzhi L, Jie P, Kun J, Yanhui Z, Jietao H, Jinxuan Y, Yan B. Preparation of elemental tellurium nanoparticles - sucrose sol and its antioxidant activity in vitro. J Wuhan Uni Technol Mater Sci Ed. 2013;28(5):1048-1052. DOI: 10.1007/s11595-0130817-z

32. Turner RJ, Weiner JH, Taylor DE. Tellurite-mediated thiol oxidation in Escherichia coli. Microbiology. 1999;145:25492557. DOI: 10.1099/00221287-145-9-2549

33. Perez JM, Calderon IL, Arenas FA, Fuentes DE, Pradenas GA, Fuentes EL, Sandoval JM, Castro ME, Elias AO, Vasquez CC. Bacterial toxicity of potassium tellurite: unveiling an ancient enigma. Plos One. 2007;2(2):1-9. DOI: 10.1371/journal. pone. 0000211 